\title{
“La fotografía es la misma muerte": Ruina, espectro y testimonio de Antonio Machado en Guerra en España de Juan Ramón Jiménez
}

\section{Citation}

Aguirre-Oteiza, Daniel. 2015. “'La Fotografía Es La Misma Muerte’: Ruina, Espectro y Testimonio de Antonio Machado En Guerra En España de Juan Ramón Jiménez." Hispanic Review 83 (4): 379-401. doi:10.1353/hir.2015.0042.

\section{Published Version}

doi:10.1353/hir.2015.0042

\section{Permanent link}

http://nrs.harvard.edu/urn-3:HUL.InstRepos:34622833

\section{Terms of Use}

This article was downloaded from Harvard University's DASH repository, and is made available under the terms and conditions applicable to Open Access Policy Articles, as set forth at http:// nrs.harvard.edu/urn-3:HUL.InstRepos:dash.current.terms-of-use\#OAP

\section{Share Your Story}

The Harvard community has made this article openly available.

Please share how this access benefits you. Submit a story.

\section{Accessibility}




\title{
“LA FOTOGRAFÍA ES LA MISMA MUERTE”: RUINA, ESPECTRO Y TESTIMONIO DE
}

ANTONIO MACHADO EN GUERRA EN ESPAÑA DE JUAN RAMÓN JIMÉNEZ

\author{
Daniel Aguirre-Oteiza' \\ Harvard University
}

\begin{abstract}
RESUMEN
El proyecto inacabado de Juan Ramón Jiménez Guerra en España puede leerse como un testimonio literario del destierro del escritor en EEUU y Latinoamérica. Entre 1936 y 1954 , Jiménez creó un archivo de materiales misceláneos propios y ajenos para documentar sus actividades en pro de la República durante la guerra civil española y el exilio. Conforme a la poética visionaria del poeta, el proyecto se articula como un montaje de ruinas epitáficas que atestiguan la experiencia de acercamiento a la muerte de Antonio Machado y de Jiménez, salvaguardando sus obras de usos políticos. Las tensiones entre política y poética que revela este montaje aclara la importante posición que estudios recientes otorgan a Jiménez en la historia intelectual de la España del siglo XX.
\end{abstract}

PALABRAS CLAVE

Juan Ramón Jiménez, Antonio Machado, José Bergamín, Poesía, Fotografía, Montaje, Testimonio literario, Memoria histórica, Fantasma, Ruina, Guerra civil española, Franquismo, Exilio.

\section{SUMMARY}

Juan Ramón Jiménez's unfinished project Guerra en España can be read as a literary testimony of his exile in the USA and Latin America. Between 1936 and 1954, Jiménez created a heterogeneous archive of his own and others' materials so as to document his activities in favor of the Republic during the Spanish Civil War and his time in exile. Following Jiménez's visionary poetics, his project can be articulated as a montage of epitaphic ruins that bears witness to the near-death experience of Antonio Machado and Jiménez, while safeguarding their works from political use. The tensions between politics and poetics revealed by this montage clarify the important place that recent studies give to Jiménez in $20^{\text {th }}$-century Spanish intellectual history

\section{KEYWORDS:}

Juan Ramón Jiménez, Antonio Machado, José Bergamín, Poetry, Photography, Montage, Literary testimony, Historical memory, Ghost, Ruins, Spanish Civil War; Francoism, Exile. 


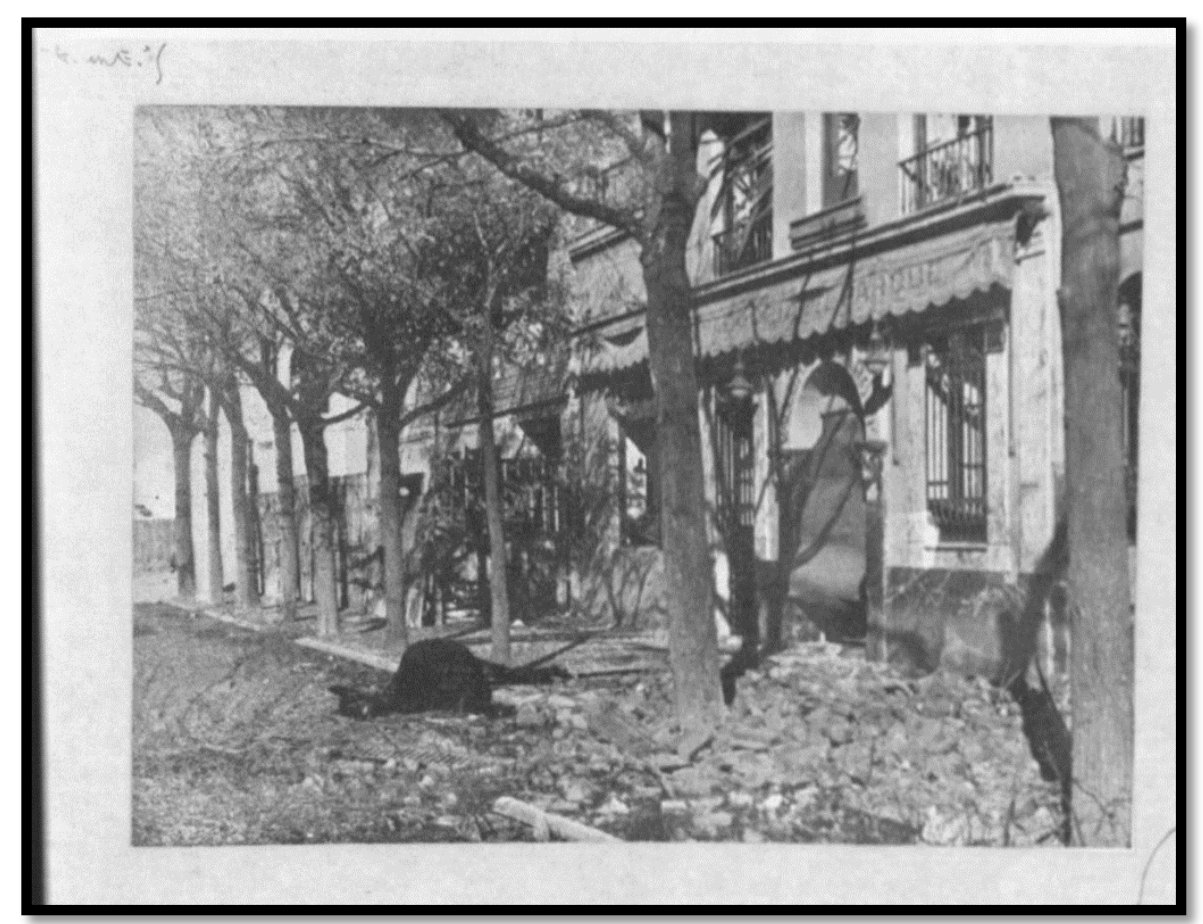

Figure 1. Fotografía, sin título, perteneciente al archivo de Juan Ramón Jiménez destinado al proyecto Guerra en España.

Reprinted with permission of Editorial Point de Lunettes.

Versos anónimos del romancero medieval. Retratos de Hitler y Mussolini. Un salvoconducto. Coplas de la canción popular "Anda jaleo, jaleo". Una conferencia titulada “Comprensión y justicia”. Una cita de un espejo de príncipes de 1292. Una traducción de un poema de W. B. Yeats. Una foto, sin título, de una calle en ruinas; otra del rostro de una niña aparentemente muerta. Poemas propios. Un recorte de prensa de 1939 con una foto de Antonio Machado y la noticia de su muerte. ${ }^{1}$ Éstas son sólo algunas muestras del heterogéneo conjunto de materiales que Juan Ramón Jiménez reunió bajo el título Guerra en España durante sus más de veinte años de exilio en Cuba, Estados Unidos y Puerto Rico. El proyecto, llamado inicialmente Español con su España (Política poética) y Desterrado, diario poético, quedó inacabado a la muerte del escritor en 1958. Jiménez mismo explicó que su objetivo era dejar constancia de su

\footnotetext{
${ }^{1}$ A menos que se indique lo contrario, todas las referencias son a Guerra en España: prosa y verso (1936-1954). En este párrafo, las páginas correspondientes son: 12, Álbum I: 77-76, 181, 12, 194, 11, 133, Álbum I: 17, Álbum I: 57, 83, Álbum I: 2.
} 
intervención "de hombre y poeta" en la política española durante la guerra civil y el destierro; esto es, su actividad social y política como "hombre de la realidad cotidiana" y su "trabajo normal" como "hombre vocativo" durante la guerra y el destierro (Crespo 10). Por tanto, el criterio que siguió Jiménez para reunir sus materiales fue la documentación de lo que cabe llamar su "biografía" y su "bibliografía", los dos polos que activan su producción escrita como trasuntos de su "vida" y de su "obra".

Por su volumen y heterogeneidad, Guerra en España ocupa un lugar de excepción no sólo en la obra de Jiménez, sino entre los relatos testimoniales publicados sobre la guerra civil española y el exilio republicano. El proyecto incorpora como prólogo "Voces de calidad", un artículo escrito por Antonio Machado previamente, en 1937, para el Servicio Español de Información de la República, donde proclama el singular carácter testimonial de la obra de Jiménez: sus palabras, indica Machado, no son sólo las de un "testigo presencial" de "la gran experiencia trágica de la España actual"; son las de un "verdadero poeta" dotado de "ojos excepcionales" que "ven en lo profundo" (7-8). Entendido como testimonio, Guerra en España se inicia después, en 1939, cuando Jiménez, exiliado en Florida, se entera de que Machado ha fallecido tras pasar la frontera de Francia al final de la guerra. Tal sería el origen emocional y simbólico del proyecto que llevó a Jiménez a crear un archivo documental pro memoria y escribir los textos de recuerdo y de denuncia que guardará hasta su muerte, ocurrida casi veinte años después.

Teniendo en cuenta el sugerido origen del proyecto, este artículo estudia el valor simbólico como testigo "espectral" que adquiere Machado en Guerra en España. Con ese propósito se explora la relación entre determinados materiales asociados al poeta conmemorado: el artículo "Voces de calidad", la foto que acompaña a la noticia de su muerte y el texto 
necrológico que le dedica Jiménez. A continuación, se analiza el tipo de testimonio de "poeta" que tal relación permite construir y extender al conjunto de Guerra en España, así como el valor que tal testimonio cobra ahora, en un campo de producción cultural definido por el interés público y académico que suscitan el pasado reciente de la historia española en general y el debate sobre la memoria histórica en particular. La tesis que proponen estas páginas es la siguiente: aunque se trata de un proyecto inacabado, el valor fundamental de Guerra en España como testimonio depende de la posibilidad de relacionar y articular los misceláneos materiales que atestiguan la labor literaria y política de Jiménez en cuanto "hombre vocativo" y "hombre de la realidad cotidiana"; esto es, el escritor comprometido con su poesía y el intelectual comprometido con la República. Jiménez era un "metamorfoseador sucesivo", según definición propia (Crespo 6). El análisis de su estética "visionaria" permitirá no sólo explicar la inclusión y, en cierto modo, metamorfosis de estos y otros materiales en el proyecto, sino establecer entre ellos vínculos capaces de abarcar los múltiples matices de la experiencia de crisis que condicionó la vida de Jiménez en su destierro americano. Como se verá, la heterogeneidad discursiva que gobierna estos vínculos se revela, en definitiva, al servicio de una homogeneidad profunda, una homogeneidad asociada al recuerdo de la muerte.

El recuerdo de la muerte es provocado por el uso político que, según Jiménez, se hace de la figura de Machado tras su fallecimiento en Francia. La lectura reduccionista de la obra machadiana que supone tal uso le sirve a Jiménez de advertencia contra el peligro de que, si él también muere en el exilio, su biografía y su bibliografía resulten asimismo distorsionadas. Esta percepción de Jiménez es clave para comprender su experiencia de crisis. Mediante la recuperación alegórica de Machado como un poeta fantasmal capaz de dar testimonio de la tragedia del pueblo español más allá de usos políticos derivados de la guerra, Jiménez intenta 
salvaguardar su propia obra de lecturas circunstanciales y asegurarse de que pueda regresar a España simbólicamente como poeta para la posteridad. En este sentido, cabe adelantar que los cambios de perspectiva que introduce Jiménez al trasladar sus materiales y entrelazarlos con los de Machado constituyen una compleja reflexión sobre la vida textual del testigo y de su testimonio; esto es, sobre la forma en que el escritor construye su biografía y su bibliografía.

Un paso importante en el regreso simbólico de Jiménez se produjo en Barcelona en 1985, pasados veintisiete años de la muerte del poeta, cuando se publicó Guerra en España por primera vez. De la edición se ocupó el escritor español Ángel Crespo, quien, también exiliado en Puerto Rico, pudo reconstruir parcialmente el proyecto de Jiménez. Su edición incluía sólo una pequeña parte de un gran archivo consistente en poemas originales, traducciones, aforismos, versos anónimos del romancero, así como conferencias, entrevistas, cartas, artículos de prensa, carteles de propaganda, fotografías, etcétera (Crespo 7). Casi un cuarto de siglo después, en 2009, el regreso simbólico de Jiménez daba un paso adelante cuando la edición de Crespo volvía a aparecer en Granada, España, revisada y ampliada hasta sumar 763 páginas y más de 159 ilustraciones. Soledad González Ródenas, responsable de la edición, calificaba el conjunto de materiales de "auténtico fárrago" (X). Con todo, en 1984 Crespo aseguraba que, por su naturaleza, el libro poseía "valor histórico y literario" $(\mathrm{X}){ }^{2}$ Además del valor relativo a los más de veinte años de franquismo y exilio a los que remiten de inmediato, las dos ediciones

\footnotetext{
${ }^{2}$ La primera edición se limita a 335 páginas y 27 imágenes. En el contexto de la memoria histórica en España, resulta significativo que, por sugerencia de la editorial Seix Barral, Crespo hubiera de recortar y modificar la edición que tenía pensada a causa de la delicada situación política que atravesaba el país a principios de los años ochenta. Así, quedaron fuera las referencias explícitas al saqueo del domicilio de Jiménez en junio de 1939 (XIX). A este respecto, Crespo escribió: "El que hoy se consiguiera ocultarlo en parte, no quiere decir que lo sea para siempre. Ya vendrán otros investigadores profundizando mucho más, y tarde o temprano se conocerá toda la verdad" (XIX). González Ródenas cumple este propósito al dedicar a referido episodio una sección de casi cincuenta páginas y restituir el título que Crespo pensó para él: "El allanamiento del piso de Madrid". La editora no sólo incorpora documentos que fueron suprimidos por razones políticas y editoriales, sino que añade otros recopilados por ella misma. Así, la sección “Álbum 2" recoge copias de recortes de periódico, fotografías y cartas del escritor, e incluso una imagen de la llegada de los restos de Jiménez y Zenobia Cambrubí a España en 1958.
} 
adquieren valor porque coinciden con dos momentos decisivos en la producción cultural sobre la experiencia de la guerra civil y la posguerra. 1985 y 2009 señalan, respectivamente, el final de la transición del franquismo a la democracia y un punto de inflexión internacional en los debates sobre la memoria histórica. ${ }^{3}$ La publicación de Guerra en España consolida así el proceso de recuperación del valor histórico de la obra de Jiménez impulsado en 1999 con la aparición de Lírica de una Atlántida, su poesía de exilio. En un contexto caracterizado por las polémicas sobre la función que desempeña la memoria en la asunción de un episodio traumático, los testimonios sobre la guerra civil y la posguerra en España cobran relevancia precisamente en función de su multiplicidad, variedad y complejidad discursiva (Hardcastle 155). El proyecto de Jiménez responde con creces a tales características.

Antonio Machado es, con mucho, el nombre más citado en Guerra en España. El autor de "Si mi pluma valiera tu pistola" se erige en protagonista del proyecto no sólo por el simbolismo que adquiere su nombre tras su muerte en el exilio, sino por la reacción que provoca en Jiménez la lectura política a la que, en su opinión, José Bergamín reduce tal simbolismo en el prólogo a su edición de las obras completas de Machado, publicadas en México en 1940. Según Jiménez, “[p]oner a una obra poética de paz un prólogo de guerra, porque las circunstancias hayan convertido en 'guerrerosa' la última parte del libro, es relegar la obra verdadera a un segundo plano, como queda relegada nuestra vida en toda circunstancia trájica [sic]" (126). En respuesta al prólogo de Bergamín, Jiménez no sólo define la "obra verdadera” de Machado, sino que se sirve de ella para transformar su figura en una alegoría del "pueblo" entendido como víctima colectiva de la "gran experiencia trágica de la España actual" (7). Para Jiménez, el valor simbólico de Machado en cuanto alegoría trasciende el valor político específico que le otorga

\footnotetext{
${ }^{3}$ En 1985 se firma el Acta de Adhesión de España a las Comunidades Europeas. En 2009 el Comité de Derechos Humanos de Naciones Unidas sugiere que se cree en España una comisión de expertos para establecer la verdad sobre las violaciones de los derechos humanos cometidas durante la guerra civil.
} 
Bergamín. En el texto necrológico que Jiménez escribe con motivo de su muerte, Machado aparece representado como un espectro, "vivo para siempre en presencia invisible" (445), capaz de pasar "los montes altos de la frontera helada" porque el "pueblo" víctima también los pasó así y, en cuanto "conocedor de los vericuetos estrechos de la muerte", de regresar a "España por el cielo de debajo de tierra" (445-46).

La figura espectral de Machado obedece a la idea de posteridad artística que promueve Jiménez. Ésta es una idea clave en su estética visionaria: se trata de la consideración "póstuma" de sus obras como "ruina secular de pasado y futuro". Según Jiménez, ciertas obras "populares", "obras de intemperie" como las del "ya duradero" Machado, poseen "una calidad particular que las hace ya parecer en el presente lo que serán en el futuro, con lo que toman aspecto de pasado" (Metamórfosis 415). El tiempo no sólo asimila estas obras a la "naturaleza", sino que las deja en “un estado más permanente, más 'eterno"” (Metamórfosis 415). Así, la "obra verdadera” de muertos como Unamuno o García Lorca puede quedar a salvo de usos circunstanciales derivados de "una realidad espantosa, pero ocasional, accidental" como es la guerra (126). Un ejemplo de obra "popular" es "Iris de la noche", que Jiménez cita en su proyecto como uno de los romances más "hondos" y “eternos" de Machado (446).

La consideración de la obra propia como "ruina secular de pasado y futuro" no obedece tanto a la nostálgica búsqueda de un origen suprahistórico o de un telos histórico cuanto a la creencia moderna en una autenticidad que conjure el peligro de falsedad y artificialidad en tiempos convulsos (Huyssen 18). Esto es, la ruina es una garantía de seguridad en tiempos de mudanza. En el caso de Guerra en España, la autenticidad del recuerdo de la muerte, el memento mori inscrito en la obra "póstuma" como forma de autenticidad da respuesta a la "falsía" que, 
según Jiménez, ha cometido Bergamín (446-47). ${ }^{4}$ El poeta defiende así la "obra verdadera" "aunque se nos vuelva todo el mundo falso en contra con calumnia, mentira y basura" (126-7). Ahora bien, en Guerra en España, el aspecto "ruinoso" de una obra poética considerada póstumamente, su calidad "popular" y "eterna", cobra relieve al aparecer yuxtapuesta a los documentos que sirven para atestiguar las circunstancias históricas concretas vividas por Jiménez. Esta tensión entre historia y obra "popular" no discrepa de la dialéctica entre historia e intrahistoria propia del institucionismo krausista, que influyó profundamente en la formación del poeta (López Castro 41). De ahí que a los materiales de su bibliografía como "hombre vocativo" (documentos de su "trabajo normal" como poeta) Jiménez yuxtaponga ahora materiales de su biografía como "hombre de la realidad cotidiana" (documentos de su activismo político durante la guerra y el exilio) (XV, Crespo 10).

El propósito de Jiménez es lograr que, al igual que la "obra verdadera" de Machado, su propia obra quede incorporada a la del "verdadero, milagroso poeta colectivo", "su pueblo", cuya tragedia trasciende, sin abolirla, la "realidad espantosa" que él mismo ha vivido y atestiguado (Política 409; 7). A tal fin sirve la yuxtaposición "en lo profundo" de las populares coplas epitáficas que abren Guerra en España ("En la calle de los Muros / mataron una paloma, / yo cortaré con mis manos / las flores de tu corona") con versos propios de tono popular como "En mi boca te aguarda tu sed, / tu sed que es la mía. / Entra, no soy seco, paloma ofendida" $(12,83)$. Los versos populares a los que Jiménez quiere sumar los suyos mantendrían viva la voz del pueblo entendido, de acuerdo con el concepto krausista, como víctima intrahistórica. De modo semejante, el poeta denuncia la capacidad de la palabra para herir, conforme a la advertencia de Sancho el Bravo que aparece citada tras el prólogo: "sanan las cuchilladas, mas non las malas

\footnotetext{
${ }^{4}$ Como argumenta Huyssen respecto a las ruinas de la modernidad, “[g]enuineness as naturalness in opposition to artificiality and the fake ... is an empirically verifiable criterion of the ruin" (15).
} 
palabras" (11-12). Tal denuncia intrahistórica no le impide a Jiménez condenar, unas páginas antes, la herida histórica concreta, el trauma de la "gran tragedia de la España actual" (7). La "ferida" es producto de la "falsía" de Bergamín, pero también se corresponde, dialécticamente, con una "mancilla" antigua, intrahistórica, infligida por una indefinida pero "terrible guerra de tres siglos" que Machado es capaz de atestiguar como alegórica "paloma de linde" (446).

Desde este punto de vista, Machado se erige en el testigo por excelencia de la "tragedia" del "pueblo" español. Guerra en España se abre justamente con su artículo "Voces de calidad", documento histórico que Jiménez incorpora a su proyecto para presentarse a sí mismo también en calidad de testigo. Este hecho es fundamental, ya que, si bien barajó otros órdenes para el resto de los materiales, Jiménez expresó en varias notas autógrafas su deseo de que el texto de Machado ocupara el primer lugar de Guerra en España. Ángel Crespo afirma que "cumple la voluntad" de Jiménez al incluirlo como prólogo de su edición (22). "Voces de calidad" siempre mantuvo un lugar prioritario en el proyecto de Jiménez, de modo que posee una importancia capital para la comprensión de Guerra en España en clave de testimonio. ${ }^{5}$ Por medio de Machado, el lector se entera de las palabras pronunciadas por Jiménez como "testigo presencial"

\footnotetext{
5 Ángel Crespo menciona tres notas autógrafas (22). Soledad González Rodenas va más allá al indicar que Jiménez expresó el deseo de que "Voces de calidad" fuera el prólogo de Guerra en España "en cinco de las notas autógrafas para su ordenación" que forman parte de los documentos pro memoria que Jiménez archivó para organizar los materiales de su proyecto (XVII). Por tanto, aunque Guerra en España es un proyecto inacabado, la organización elegida por Crespo y González Rodenas no es enteramente caprichosa. El valor que Jiménez atribuía a Antonio Machado y a "Voces de calidad" en la construcción de la imagen de sí mismo que quería dejar a la posteridad se ve confirmado en otro proyecto inacabado a la muerte del escritor: Vida. Como indican Mercedes Juliá y M $\mathrm{M}^{\mathrm{a}}$ Ángeles Sanz-Manzano, editoras del primer volumen del mismo, el artículo de Machado estaba destinado a abrir otro de los volúmenes que lo integraban, "según una de las ordenaciones pensadas" por Jiménez (744). Jiménez también pensaba incluir en Vida una respuesta a "Voces de calidad" donde quería añadir "lo malo", es decir, los aspectos espinosos de su relación con Machado (744). Esta respuesta no aparece en Guerra en España, pero sí en la edición de Vida preparada por Juliá y Sanz-Manzano. Por todo ello cabe juzgar Vida y Guerra en España como proyectos complementarios dentro de lo que Juliá y Sanz-Manzano denominan "el vasto corpus de la escritura autobiográfica de Juan Ramón Jiménez" (20). Ambos proyectos fueron concebidos, en parte, para satisfacer "la necesidad de defenderse contra malentendidos y aclarar para la posteridad problemas habidos con los discípulos y críticos que lo habían 'calumniado' en España” (Juliá y Sanz-Manzano, 18). En este sentido, Vida y Guerra en España responden a un impulso testimonial. Guerra en España se centraría en aclarar, con documentos heterogéneos, la actuación de Jiménez en la guerra civil.
} 
de la "loca fiesta trágica" que fue Madrid en 1936 (7). Estas palabras de Jiménez Machado las extrae en 1937, en Valencia, de "Comprensión y justicia", conferencia que Jiménez ha dictado un año antes en Nueva York para defender a la República y explicar su salida de España. Tres años después, en 1939, cuando se entera del fallecimiento de Machado, Jiménez escribe que Machado fue víctima de la muerte sufrida por el pueblo en el exilio. Machado, dice Jiménez, murió "colectivamente, res mayor de un rebaño humano perseguido, echado de España" (445). Como víctima de una muerte colectiva, Machado le sirve a Jiménez para enmarcar su propio testimonio de la tragedia del pueblo: “'Como una violenta unión con la verdad', nos define Juan Ramón aquel ímpetu popular” (8). Esto es, el poeta fallecido, Machado caracteriza el testimonio del poeta vivo, Jiménez, en el plano biográfico al citar precisamente unas palabras de éste que constituyen la definición de testigo por excelencia: "yo lo he visto" (Ricoeur 164).

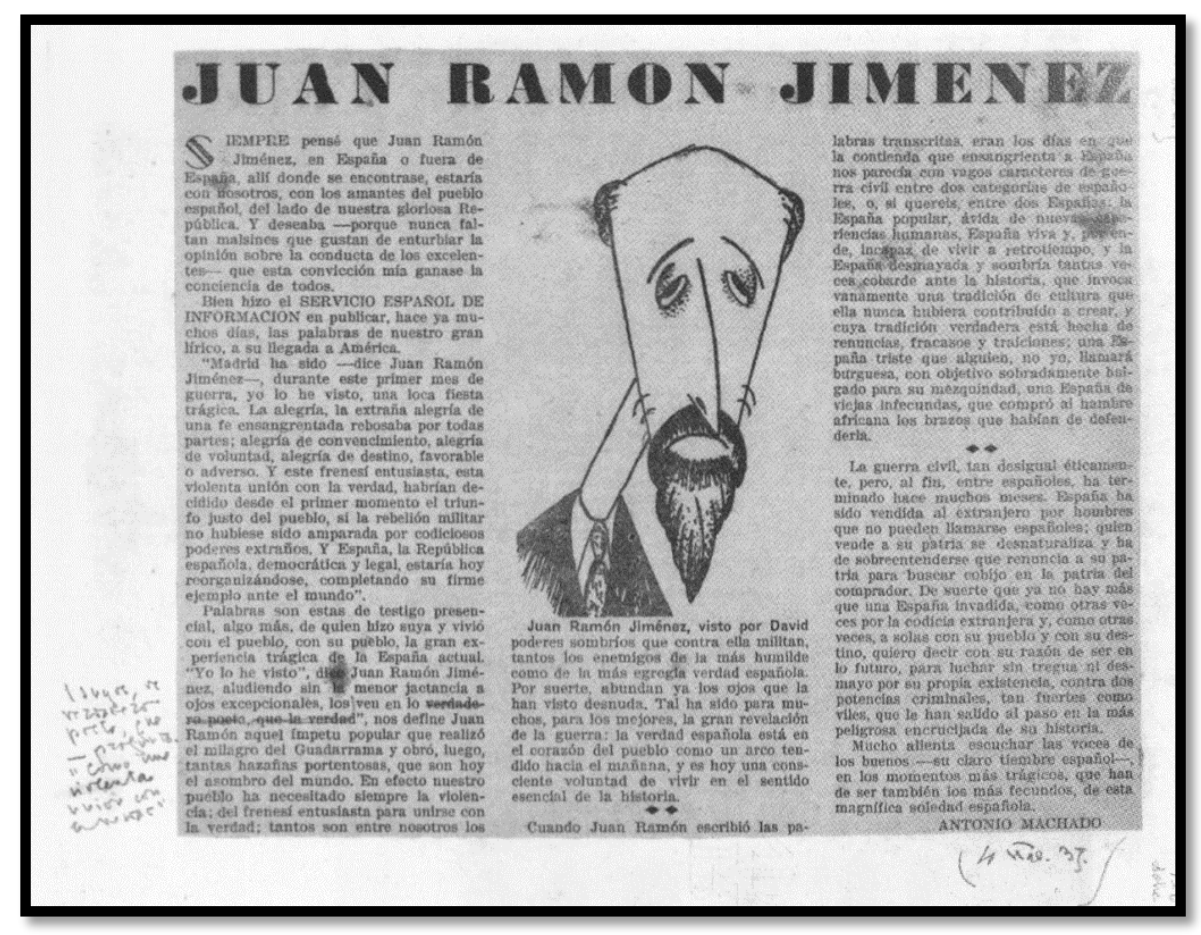

Figure 2. "Voces de calidad", artículo de Antonio Machado en favor de Juan Ramón Jiménez, publicado en Valencia el 12 de septiembre de 1937. Este recorte del artículo, publicado en La Habana en 1937, forma parte del archivo de Juan Ramón Jiménez. Reprinted with permission of Editorial Point de Lunettes. 
Así, el texto de Machado se revela como un testimonio de excepción no sólo porque él también ha sido un testigo constantemente presencial de la guerra (la ha visto con sus propios ojos), sino porque define el acto testimonial y además señala la existencia de un colectivo anónimo de testigos: "abundan ya los ojos que ... han visto desnuda [la verdad]" (8). Esta “abundancia de ojos" aparece reinscrita en medio de los diversos materiales que integran Guerra en España: las palabras testimoniales de Jiménez extraídas de su conferencia de 1936 reaparecen enmarcadas en el artículo de Machado de 1937 que, significativamente, precede a la serie de romances populares y anónimos que Jiménez sitúa al principio de su proyecto. Si como indica el escritor en las notas autógrafas de su archivo, en distintos lugares los mismos "escritos tienen un sentido distinto", el artículo de Machado leído, ahora, como prólogo sirve para autorizar no sólo el citado testimonio de Jiménez, sino el proyecto en su conjunto; esto es, las diversas "voces de calidad" que resuenan a lo largo de él (Crespo 2). En este sentido, Guerra en España adquiere valor testimonial también en el plano histórico y bibliográfico gracias a la autoridad conferida por el testimonio de Machado que lo prologa.

Con todo, las palabras de Jiménez no son sólo las de un mero "testigo presencial": constituyen un testimonio de "poeta" (7). Esto es, sus palabras forman parte del colectivo de quienes ven con "ojos excepcionales" "en lo profundo", de manera que su voz se corresponde con las "voces de los buenos" (9). A Jiménez no le basta con ser testigo presencial de la tragedia: desea añadir su voz de exiliado a las voces del anónimo "rebaño humano perseguido, echado de España”, que representa Machado, y para ello necesita las palabras del testigo colectivo muerto en el exilio. Por este motivo Jiménez incorpora su testimonio al que prestan los poetas por excelencia: Machado, el "verdadero poeta nacional", y el pueblo, cuyos poemas integran la obra del "verdadero, milagroso poeta colectivo" (232; Política 409). 
Los textos de Machado y de Jiménez remiten a lugares y momentos diversos: Nueva York en 1936, Valencia en 1937, Francia en 1939, Florida el mismo año, México en 1940 y, también, con la publicación de Guerra en España, Barcelona en 1985, Granada en 2009. El juego de espejos que se produce entre estos lugares y momentos es coherente con la poética visionaria, el montaje de perspectivas del Jiménez metamorfoseador. El acto de habla testimonial por excelencia - "yo lo he visto" - cambia, efectivamente, de sentido en cuanto cambia de lugar. El testimonio de la conferencia que Jiménez dicta en Nueva York está, literalmente, en primera persona: palabra en acción, acto de habla, petición de justicia leída en voz alta por el testigo ante un público, con el propósito de provocar otra una reacción contra la política de no intervención en la guerra. Por otro lado, trasladada a Guerra en España, esa misma conferencia adquiere un valor de recuerdo de esa acción y, también, retrospectivamente, de la injusta falta de reacción por parte de la comunidad internacional a la que se dirigió el escritor. En el prólogo de Machado también aparece el testimonio de Jiménez en primera persona, pero indirectamente, a través de los ojos y las palabras del Machado lector. El texto de Jiménez, donde leemos que "abundan ya" los ojos y las voces —esto es, los testigos y los testimonios—, se erige entonces en el testimonio de un poeta que recuerda varias injusticias: por un lado, la que Jiménez denuncia en su conferencia de 1936 (recogida en el testimonio escrito en 1937 por Machado, el testigo por excelencia que ha fallecido injustamente en el exilio en 1939); por otro, la injusticia que se comete contra él cuando su testimonio y su trabajo en defensa de la República caen en el olvido.

Y es que Jiménez también desea asegurarse la posteridad de su propia obra. El propósito evidente de su proyecto es poner coto a la imagen de poeta fantasmal que otros escritores difunden de él, imagen de signo contrario a la de Machado muerto. Se trata de la imagen del poeta encerrado en su torre de marfil $(X, 42)$. Es más, durante los años de posguerra Jiménez 
cobra fama no sólo de poeta aislado, sino de moribundo o muerto en vida. En 1951, Ramón Gómez de la Serna compara su aislamiento con "la fría paz de los sepulcros" (Blasco y Piedra 158). A Jiménez el reconocimiento de su obra no le basta si no se corresponde con el de su vida. Sin embargo, en 1953 José Moreno Villa sentencia: "Grande obra ha dejado, pero gran vida ha perdido" (XCVIII). A fin de atestiguar la correspondencia entre biografía y bibliografía, Jiménez invierte esta imagen de poeta fantasmal en el texto necrológico que incluye en Guerra en España con Machado por protagonista. El poeta también se acerca al fallecido al escribir un epitafio apócrifo para anunciar su propia muerte en circunstancias semejantes a las que rodearon la de Machado: "Murió y fue enterrado en Font Romeu, Francia / el 18 de julio de 1936 / a los 48 años" (717). Con arreglo a este espíritu epitáfico, Jiménez cumple un antiguo deseo suyo, de ascendencia romántica y simbolista, expresado entre 1897 y 1909: ver sus libros sub especie aeternitatis, como obra verdadera, "como si ya nos hubiéramos muerto y nos acordásemos de nosotros" (Metamórfosis 48). Este deseo se corresponde con el expresado en un apunte escrito más de treinta años después, en fecha cercana a la guerra: “iSi yo pudiera sobrevivir a mi muerte, sólo para definir lo acabado por ella!” (Metamórfosis 496).

Ahora bien, Jiménez no sólo complica su testimonio al trasladar los materiales escritos propios y entrelazarlos con otros ajenos. Las posibilidades metamórficas y conmemorativas de su proyecto se multiplican gracias a la yuxtaposición añadida de textos e imágenes. En efecto, las diversas visiones o perspectivas que ofrecen los abundantes "ojos excepcionales" se articulan con el juego de miradas que sugiere una imagen en concreto: la foto que acompaña a un recorte de periódico que recibe Jiménez en 1939. El titular de la noticia reza: "Murió el poeta español Antonio Machado". Si Jiménez se presenta como testigo con un montaje de materiales propios y ajenos que invitan a ver "en lo profundo", la foto de Machado invita, como dice Jiménez, a un 
“entrever" que es "más que ver" y es, incluso, "verlo todo", más allá y más acá de la mera imagen; supone trasladar la foto y trasladarse uno mismo imaginativamente en el tiempo y en el espacio para tener presente y conmemorar lo que en uno y otro caso constituye una ausencia respecto a la experiencia del testigo (Metamórfosis 639). Este tipo de traslados, este juego de perspectivas, forma parte constitutiva de la poética visionaria de Jiménez: "Yo quiero parar, clavar los ojos en las cosas, verlas a ellas; pero las traspaso sin querer, son sólo un cristal para mí, les veo lo de detrás ¡ay! a través de ellas" (Metamórfosis 336).

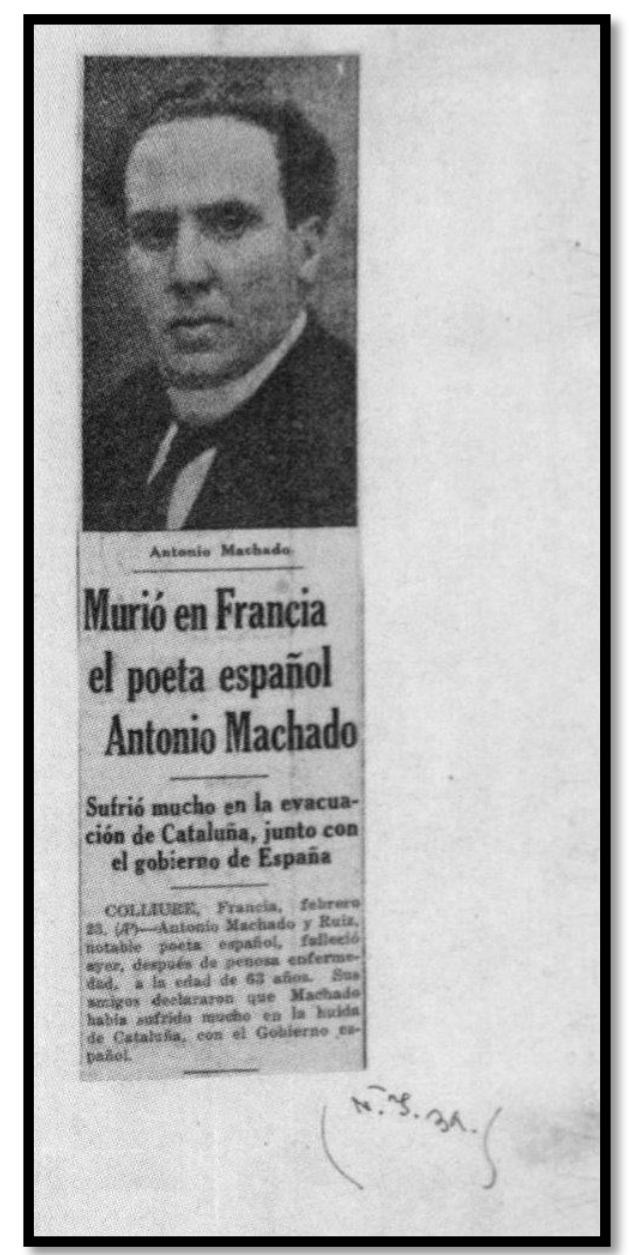

Figure 3. Recorte con la noticia de la muerte de Antonio Machado. Juan Ramón Jiménez lo guardó en el archivo de Guerra en España. La nota manuscrita dice "N[ew] Y[ork]. 39". Reprinted with permission of Editorial Point de Lunettes. 
En la foto de Machado Jiménez vería, evidentemente, al Machado ausente: doblemente ausente por muerto y por retratado. Pero si “entrever es más que ver” porque "es ver sin peligro de muerte de lo visto", Jiménez también imaginaría a Machado "vivo": detrás de la foto entrevería al poeta que había conocido antes de la guerra (Metamórfosis 639). Ahora bien, cambiando de perspectiva, Jiménez también reconocería a Machado, al mismo tiempo, como un muerto precisamente porque estaba retratado. Y es que Jiménez creía que la fotografía era "la misma muerte": "Jamás he visto dos fotografías de una persona que se parezcan entre sí, lo que quiere decir que ninguna se parece a la persona" (Metamórfosis 379). Conforme a esta lógica, si el Machado de la foto murió en 1939, Jiménez no lo "reconocería” como tal. Lo que acaso reconocería es otra imagen: la imagen del poeta joven. Efectivamente, aunque carente de fecha, la fotografía del recorte recuerda a otra fotografía casi idéntica que Machado dedicó a Jiménez un cuarto de siglo antes, en 1913, foto que no está en Guerra en España. Al ver la foto del recorte de 1939, Jiménez entrevería al joven de 1913. Pero lo entrevería como muerto. Y es que también la foto dedicada de 1913 sería "la misma muerte", dado que ninguna foto "se parece a la persona”. En consecuencia, la tensión entre noticia y fotografía ahonda la impresión de ausencia y, por tanto, el recuerdo de la muerte.

Tal recuerdo de la muerte pudo traer consecuencias aún más profundas para Jiménez. Si la foto del recorte de 1939 le recordó, espectralmente, a otra foto de 1913 dedicada a él, Jiménez también se convertiría en espectro. La fotografía supone la caducidad de la experiencia: la cercanía de la imagen equivale a la distancia de lo vivido. Y es que, como sostiene Roland Barthes, el testimonio de la fotografía "bears not on the object but on time" (88). Esto es, al quedar identificada con "la misma muerte", la foto de Machado ofrece "a glimpse of a history to which we no longer belong" (Cadava xxviii). A modo de punctum barthesiano, lo que punza, lo 
que traspasa la visión del Jiménez desterrado, en Nueva York, es la imagen espectral de unas historias irremediablemente pasadas, la de Machado y la suya propia. La espectralización se multiplica en el espacio para el poeta exiliado y en el tiempo para el poeta que conoció a Machado en 1913. Es más, cuando ve la foto, a Jiménez le resultan inalcanzables tanto el pasado del destierro de Machado en Francia en 1939 como el pasado de la relativa paz que vivía España en 1913, cuando se vieron los amigos. Además, Jiménez logra, como diría Barthes, una "microvisión" de su muerte futura: la fotografía es un memento mori en la medida en que anuncia ya nuestra ausencia (Barthes 14; Cadava 8).

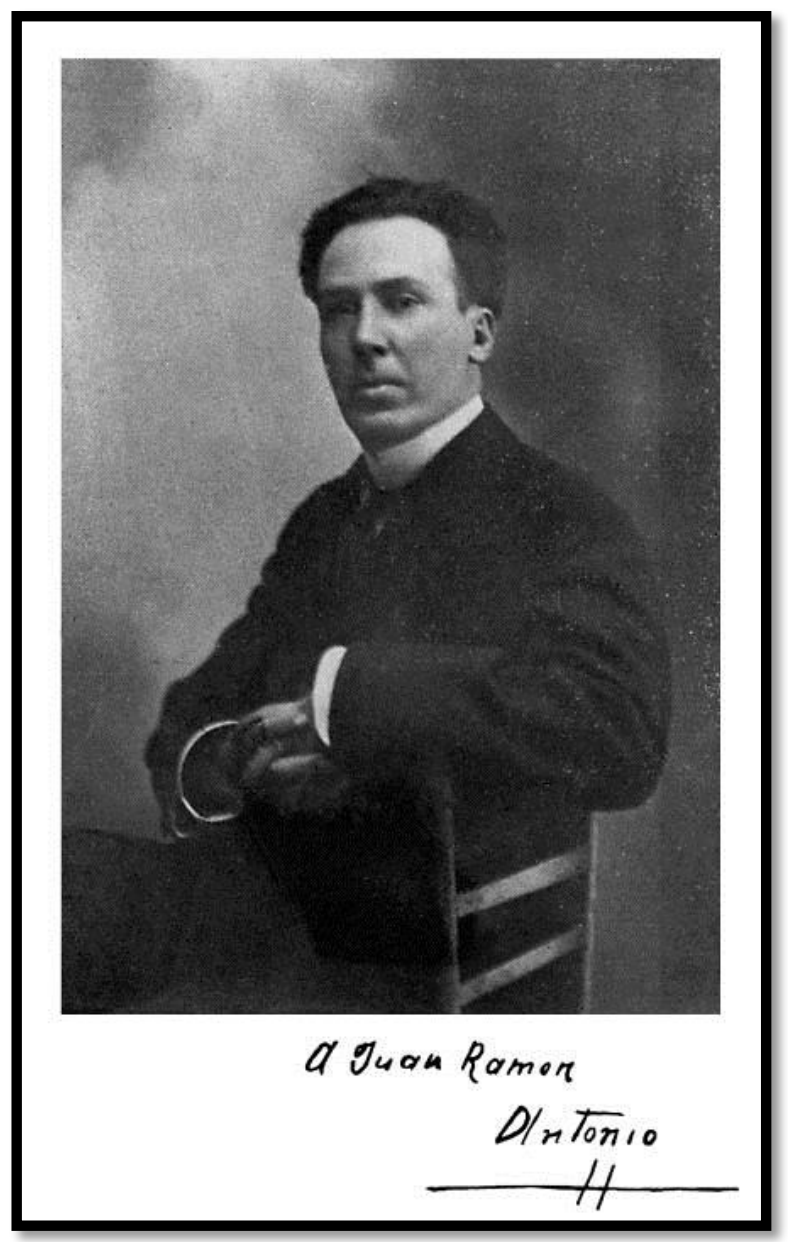

Figure 4. Retrato de Antonio Machado en 1913

Source: http://www.abelmartin.com/album/album.html 
La espectralización es, por tanto, exponencial: se multiplica hacia el pasado y hacia el futuro, hasta tocar al observador que trate de ver "en lo profundo" una historia a la que no pertenece. No es de extrañar, por tanto, que Jiménez sintiera predilección por obras "póstumas" como las de Machado, las mencionadas ruinas "de pasado y futuro" poseedoras, como se ha indicado, de "una calidad particular que las hace ya parecer en el presente lo que serán en el futuro, con lo que toman aspecto de pasado" (Metamórfosis 415). Tanto el pasado como el futuro quedan fuera del alcance del poeta, a menos que recurra a la ficción de una obra capaz de atestiguar "en lo profundo" de su compleja visión espectral de Machado y de sí mismo. De ahí que el proyecto de Jiménez incluya obras suyas en calidad de "hombre vocativo": por ejemplo, una traducción de un texto de Walter Pater en que se describe a Mona Lisa como "muerta varias veces" y conocedora de "los secretos de la tumba" (137). De ahí que componga el mencionado epitafio apócrifo, tan espectralmente machadiano. De ahí, también, que escriba un texto necrológico en el que Machado aparece no sólo como un muerto en vida antes de la guerra, sino como un espectro que, tras ser enterrado en el exilio, es capaz de ir y venir sin dificultad entre tiempos y espacios diversos.

Más allá de la evidencia de "la misma muerte" que le presenta la foto, Jiménez quiere "entrever" a un Machado capaz del "natural milagro poético" de la resurrección. Con este propósito Jiménez escribe el curioso texto necrológico en el que invoca al Machado de antes de la guerra, el poeta fantasmal que "tuvo siempre tanto de muerto como de vivo" (444). Para evitar que cualquiera se apropie de su verdadera "voz" (como, a su juicio, hace Bergamín en su edición mexicana), Jiménez trata de liberársela recurriendo a la figura dominante del discurso epitáfico, la prosopopeya: la ficción de la voz de ultratumba (446) (de Man 78). Su texto necrológico literaliza esta ficción al conmemorar a un Machado como un fantasma capaz de salvar, "viviendo 
y muriendo, la distancia de las dos únicas existencias conocidas” (444). Así, Jiménez, el poeta superviviente en el exilio, trata de "resucitar" a Machado, el poeta muerto, construyéndole una voz memorable: una "voz de calidad", eterna, que le proporcione una vida póstuma que lo libere de la muerte biográfica en Francia y de la "sobremuerte" bibliográfica; esto es, de la "falsía" cometida por "aprovechadores de cadáveres y de famas” como José Bergamín. (126).

Jiménez trata de combatir una "falsía" de palabra, según la cita de Sancho el Bravo que acompaña al prólogo. La "falsía" cometida es doble: por un lado, intenta calificar la poesía de Machado como una función exclusiva de su actividad política, echando en olvido su auténtica obra literaria "popular", y, por otro, intenta calificar la poesía de Jiménez como una función exclusiva de su obra literaria, echando en olvido su auténtica actividad política a favor del “pueblo" y de la República (447). Frente a tal simplificación, Jiménez busca ahora, como testigo ideal, la forma de "verlo todo": quiere "ver sin peligro de muerte de lo visto", más allá de la "realidad cotidiana" de la guerra y el exilio (Metamórfosis 639). Machado equilibró vida y muerte porque lo vio todo, como "todo lo vi[o]", por ejemplo, el aviador irlandés protagonista del poema de W. B. Yeats que Jiménez, "vocativo", traduce e incluye en Guerra en España (133). La simetría existencial que identifica Jiménez en Machado se corresponde con el paralelismo quiástico de la prosopopeya (Riffaterre 112). En este sentido, la figura que articula la voz de ultratumba produce una espectralización semejante a la del memento mori fotográfico. Si es capaz de imaginarse a Machado "amortajado" en vida, Jiménez puede además imaginarse a sí mismo muerto: "No soy más que un sepulcro lleno de todos mis cadáveres" (Metamórfosis 319). Y, también, al imaginar la resurrección de Machado, Jiménez puede imaginar la suya propia: “¿Morir? ‘Yo’ no he de ser enterrado. A la tierra no irá más que mi cáscara” (Metamórfosis 443). La escritura necrológica cumple así un propósito conmemorativo doble: el poeta vivo evita que 
muera la voz del poeta muerto al tiempo que se asegura de que su propia voz sobreviva cuando él muera.

Premonitoriamente, entre 1900 y 1909 Jiménez apostrofa a un anónimo tú al que llama “el muerto”: "ya no tengo más vida que la que me des tú. ¡Acuérdate de mí!” (Metamórfosis 119). Ahora, el uso de la prosopopeya permite al poeta desterrado escribir su propia vida póstuma (de Man 78). Al resucitarlo con sus palabras, Jiménez está seguro de que Machado, “conocedor de los vericuetos estrechos de la muerte, ha podido pasar a España por el cielo de debajo de tierra" (446). Las simetrías inscritas en la prosopopeya le permiten imaginarse en el exilio la posibilidad de regresar a España a través de su obra. De ahí que la voz de Machado y la suya formen parte de "las voces de calidad" que prologan su proyecto. Jiménez morirá del "todo en figura" como Machado, que ahora yace "podrido en la tierra" (446). Pero, aunque desaparezca su “cáscara", su proyecto servirá de máscara fúnebre para que su "yo" no quede enterrado y la figura de su voz perviva, "verdadera", incluso más allá de la "frontera helada", en España.

En resumen, para combatir las "falsías" que otros escriben sobre Machado y sobre su persona, Jiménez reinscribe en Guerra en España dos testimonios de la muerte y la "sobremuerte" de Machado: por un lado, un testimonio documental de su fallecimiento y de la posterior politización de su obra; por otro, un testimonio poético de sus metamorfosis de fantasma y de la recuperación póstuma de su obra para la poesía "verdadera", la poesía colectiva del pueblo. Desde este ángulo, las "voces de calidad" son voces de "testigo presencial" en dos sentidos: el activista, "hombre de la realidad" cotidiana, que ve la tragedia de Madrid y, simultáneamente, el poeta, "hombre vocativo", que ve "en lo profundo" de la muerte. Guerra en España contiene otros materiales que acreditan ambos testimonios. Los documentos biográficos del primer testimonio, los que atestiguan la labor política de Jiménez, saltan a la vista: 
conferencias, fotografías, declaraciones, un salvoconducto, etcétera. Menos evidentes son los materiales de su "trabajo normal" de poeta. Estos documentos bibliográficos dan fe de la singular experiencia de acercamiento a la muerte que vive Jiménez: constituyen la ficción de un testimonio imaginario que le permite afirmar que Machado "resucitaba cada día ante los que lo vimos". Jiménez, dice, vio al fantasma de Machado. Este testimonio es, efectivamente, un “milagro poético". Ejemplos de estos materiales son la mencionada necrológica, pero también sus traducciones de los poemas funerarios de Yeats y Russell, los versos anónimos y populares ("las flores de tu corona" de "Anda, jaleo, jaleo" son flores de corona funeraria) y, especialmente, su poema "Espacio", que, trasladado a Guerra en España, ofrece una nueva reflexión sobre una vida vista y escrita como "ruina que persiste" o "muerte en movimiento" entre América y España $(135,111)$. Todos estos materiales representan otras tantas voces para la posteridad de Jiménez: constituyen la prosopopeya o máscara fúnebre por la que el poeta habla en su vida póstuma y construye su insólito testimonio.

Poco antes de morir en su destierro de Puerto Rico, Jiménez califica de "calidoscopio" y de "metamórfosis $[$ sic $]$ constante" la labor que le queda por hacer con los varios libros que tiene proyectados (Metamórfosis 701-2). El heterogéneo "calidoscopio" discursivo que constituye Guerra en España en concreto enlaza con la vertiente políticamente comprometida de las vanguardias históricas. Frente a las rígidas convenciones épico-líricas de la poesía de circunstancias y la memoria moral que definen muchos poemas testimoniales sobre la guerra civil en España durante el conflicto y las décadas inmediatamente posteriores, el proyecto de Jiménez recuerda a obras de contenido heterogéneo y difícil definición genérica producidas en tiempos de conflagración o destierro (Siles 230-3). La complejidad del testimonio que estas obras presentan obedece al ambicioso proyecto de, como diría Jiménez, "verlo todo": esto es, 
articular documentos diversos capaces de forma que atestigüen las múltiples vicisitudes personales, literarias y políticas que vive el testigo en tiempos de crisis (Metamórfosis 639). Un ejemplo es el Diario de trabajo de Bertolt Brecht, compuesto entre 1934 y 1955 con anotaciones, poemas, citas, fotografías y recortes de prensa. A grandes rasgos, los diarios de Jiménez y de Brecht son obras de ascendencia vanguardista, montajes ensamblados sobre la marcha como respuesta a circunstancias históricas extremas que exigen activar simultáneamente múltiples prácticas discursivas. Así, los materiales que uno y otro poeta van reuniendo conforman y simultáneamente transforman una ambiciosa obra en marcha con arreglo a una estética abierta de índole “exploratoria y prismática”. Los poetas aspiran así a satisfacer determinadas "exigencias formales" sin dejar por ello de intervenir "en el terreno de los análisis y de las tomas de posición" que reclama la coyuntura política del momento (Didi-Huberman 15, 16, 29, 31).

En el caso de Brecht, tal exigencia formal quedará fijada en otro texto, el $A B C$ de la guerra, montaje que combina imágenes extraídas de los medios de comunicación con epigramas de cuatro versos de cosecha propia. Extrapolando la lectura que hace Georges Didi-Huberman del diario de Brecht, se diría que Jiménez "recorta y pega, aquí y allá, en el cuerpo o el flujo de su pensamiento asociativo" (31). Su proyecto queda, no obstante, sin completar. Aunque Jiménez aspirase a definir su obra para la posteridad, su testimonio de la guerra y el destierro termina erigiéndose en un cúmulo de restos. No se trata de una paradoja. Jiménez, el "metamorfoseador sucesivo", veía sus escritos como meros "borradores" de lo que deseaba llevar a cabo (Metamórfosis 95). Así, al igual que la obra de Machado, su proyecto se reduce a una "ruina secular de pasado y futuro" toda vez que, como obra inacabada, define la exigencia formal de “entrever" en sus materiales desde diversos momentos y lugares. La estética visionaria de Jiménez invita a atisbar tanto en lo "profundo" de sus fragmentarios documentos biográficos y 
bibliográficos, como entre unos y otros: en la foto y la necrológica de Machado y, también, en la relación entre una y otra. Esta visión resulta evidente en el caso de las fotos y los poemas de ruinas incluidos en el proyecto. ${ }^{6}$

Es precisamente la exigencia visionaria que supone la obra entendida como ruina póstuma lo que permite a Jiménez intervenir críticamente en la política del momento. Aprovecharse, como en su opinión hace Bergamín, de que "las circunstancias hayan convertido en 'guerrerosa' la última parte" donde reúne las obras de Machado equivale a tomar partido político en detrimento de la "obra verdadera". El tipo de multiplicidad que presenta su proyecto indica una posición crítica similar a la que, según Didi-Huberman, presenta el montaje en Walter Benjamin: "ahí donde el partido impone la condición preeminente de una parte en detrimento de otras, la posición supone una co-presencia eficaz y comprensiva, una dialéctica de las multiplicidades entre ellas" (145). Frente a la toma de partido de Bergamín, Jiménez toma posición. A la fragmentación reductora, homogénea y partidista de Bergamín, Jiménez opone una fragmentación múltiple, heterogénea y polifacética. Y es que la múltiple relación dialéctica entre poemas, fotos, conferencias, traducciones y citas responde a una idea de autonomía artística amplia, de carácter ético y político. De ahí que el proyecto de Jiménez se subtitulara inicialmente Política poética. Parafraseando a Jacques Ranciére, Jiménez propone una igualdad democrática de materiales conforme a la premisa igualitaria del "todo habla" que define la estética de la modernidad desde Flaubert: una desjerarquización de la relación entre fondo y forma a contracorriente de las premisas convencionales sobre la relación de necesidad entre uno y otra (Politics 19, 53-7). Estas premisas alimentaron en su época el debate, en el que Jiménez se vio envuelto, sobre la autonomía del arte o su sumisión a la política. En función de semejante igualdad de materiales, el lector de Guerra en España se ve en la necesidad de cambiar

\footnotetext{
${ }^{6}$ Véase, por ejemplo, la fotografía 17 en “Álbum I” y la traducción "Parque de Coole, 1929”, de W. B. Yeats (134).
} 
constantemente de perspectiva entre los materiales. Mediante estos cambios puede adoptar la posición crítica que le permita al mismo tiempo ver las ruinas dejadas por una época de crisis y “entrever" la muerte que las ronda.

En el contexto específico de los debates sobre la memoria histórica en España, el "calidoscopio" que conforman los materiales reunidos por Jiménez redestribuye lo visible, lo decible y lo posible, lo que cabe percibir y expresar en referencia a la guerra civil y el franquismo, y, en consecuencia, cómo y qué cabe recordar al respecto (Rancière 2). En Unearthing Franco's Legacy, el volumen de ensayos sobre el impacto de la guerra en la sociedad española actual publicado en 2010, Carlos Jerez-Farrán y Samuel Amago plantean la necesidad de que España "revise its past and publicly confront Franco's legacy" (5). Guerra en España constituye en este marco una excepcional aportación al debate público sobre la memoria de los muertos por la heterogeneidad discursiva que presentan los documentos biográficos y bibliográficos que lo integran. Y es que la estética visionaria que articula el archivo de Jiménez revela de manera insólita "the power of the dead to speak beyond language as they mutely but eloquently remind the nation of the crimes perpetrated against its own people during and after the Civil War“ (Jerez-Farrán y Amago 1). Desde este ángulo, cabe extrapolar las palabras de Germán Labrador en su reseña del mencionado volumen y afirmar que Jiménez impide que "naturalicemos nuestras condiciones de percepción y nuestro conocimiento de las culturas del pasado, de los archivos que de él disponemos y de las articulaciones que en ellos se han dado entre lo público, lo privado y lo íntimo" (382).

Si en los años sesenta críticos como José $\mathrm{M}^{\mathrm{a}}$ Castellet tacharon la poesía de Jiménez de carente de "vigencia histórica" frente al compromiso ético y político de la obra de Machado (29), la recepción que ha merecido Guerra en España adjudica a su autor un lugar central en la 
historia intelectual de la España del siglo XX. Así lo indican los estudios de Jordi Gracia, Ian Gibson y Andrés Trapiello, destacados entre los numerosos trabajos que han aparecido en los últimos años sobre la relación entre cultura y política durante la guerra civil y el franquismo y pasos decisivos en el regreso simbólico a España que Jiménez deseaba. En Las armas y las letras (1996, 2010), ensayo de Trapiello, Jiménez se erige en referencia clave para dilucidar la relación entre literatura y política durante la conflagración. Y ello gracias a Guerra en España, que Trapiello considera "crucial" en la obra de Jiménez y sitúa entre "los testimonios más lúcidos e impresionantes que se hayan escrito sobre la guerra" (Armas 100). Jiménez también constituye un nombre clave en La resistencia silenciosa (2004), ensayo de Gracia sobre la cultura española durante el franquismo. Trapiello y Gracia se sirven de materiales extraídos de Guerra en España para argumentar su reivindicación de la figura pública de Jiménez. En sus respectivos ensayos, el poeta aparece como representante modélico de escritor leal a la República y de opositor al franquismo en el exilio. Ambos ensayistas coinciden en subrayar la conjunción de ética y estética que persigue Jiménez en su quehacer intelectual. El hecho de que ambos ensayos hayan obtenido un gran éxito de ventas y recibido importantes premios resulta significativo en el campo cultural de la memoria histórica, marcado como está por la necesidad de "explicar de una manera no mitológica las condiciones de visibilidad e invisibilidad de las representaciones del pasado franquista y de su violencia fundacional" (Labrador 381$).{ }^{7}$

Guerra en España adquiere valor en este marco no sólo por las circunstancias que rodearon su publicación en 1985 y 2009, sino por la justa recuperación de la figura pública del Jiménez desterrado — prácticamente invisible durante la segunda mitad del siglo XX — a la que han contribuido los mencionados ensayos. De este modo cobra visibilidad la faceta biográfica del

\footnotetext{
${ }^{7}$ La resistencia silenciosa ganó el premio Anagrama de ensayo en 2004. Las armas y las letras obtuvo el Premio don Juan de Borbón en 1995.
} 
poeta como intelectual comprometido con la causa de la República, la denuncia de los horrores de la guerra y la oposición al franquismo. Al mismo tiempo, también resultan patentes las disputas por la apropiación ideológica del legado de Machado como testigo ineludible de la tragedia republicana y, asimismo, por el lugar que debe ocupar Jiménez con relación a él en la historia intelectual de la España reciente. Gracias a Guerra en España, Machado y Jiménez se erigen, junto a García Lorca y Miguel Hernández, en importantes lugares de la memoria en el marco de las representaciones del franquismo y el exilio. Prueba de ello es Cuatro poetas en guerra, el estudio que dedica Gibson —otro autor destacado en el contexto de los debates sobre la memoria histórica en España—a estos importantes poetas leales a la República.

Con todo, la principal razón por la que autores como Gibson, Gracia y Trapiello conceden importancia al "valiosísimo" conjunto de materiales es el carácter documental que adquieren respecto del papel personal que Jiménez desempeñó en la historia política y cultural española durante el periodo comprendido entre la guerra y la muerte del escritor (Trapiello, Armas 99). Guerra en España no les merece atención en cuanto parte integrante de la obra literaria —o bibliográfica — juanramoniana, sino como mero archivo del que extraer información que acredite la conducta ética del escritor. Es más, estos autores no observan posibles vínculos entre estos materiales y otros que atestiguan la labor de Jiménez como lector, traductor y editor, además de como poeta y prosista. En su reivindicación, Trapiello advierte que "la óptica de la guerra, y su desenlace ... trocó no pocas de las visiones sobre obras y personas, desenfocándolas, de suerte que cuando se habla de poesía y literatura en realidad se habla de política" (Armas 1617). Significativamente, el ejemplo que Trapiello aduce es la mencionada crítica que dirige Jiménez a Bergamín. El debate en torno al valor de la obra de Machado que propone Jiménez alerta justamente sobre el peligro que supone desenfocar nuestra visión para dotar a Guerra en 
España de un valor exclusivamente documental respecto a su intervención de "hombre y poeta" en la política del momento. Con este enfoque se corre el riesgo de perder de vista cómo la compleja poética visionaria de Jiménez modula profundamente la forma de representar su intervención en política y viceversa. La recepción de los materiales que integran su proyecto a más de medio siglo de la muerte de Jiménez resulta miope si no se recuerda la estética "visionaria” con la que el escritor trataba de asegurarse una larga vida de fantasma: “Morir? 'Yo' no he de ser enterrado. A la tierra no irá más que mi cáscara” (Metamórfosis 443).

En la segunda edición de Guerra en España, la fotografía 57, titulada "El resultado", muestra a una niña de rostro cadavérico. Al igual que el espectro de Machado que Jiménez pinta en su texto necrológico, el rostro parece tener "tanto de muerto como de vivo" (444). La imagen de la niña representaría la máscara fúnebre de una víctima de la guerra civil; esto es, representaría lo que Walter Benjamin denomina la facies hippocratica de la historia, la cara que se presenta ante los ojos del espectador como "paisaje primordial petrificado" (385). Un paisaje semejante sugieren "los montes altos de la frontera helada" que pasa el espectro de Machado en el texto necrológico. Acompañados del "poeta de la muerte", estos "montes" primordiales llegan hasta Jiménez, exiliado al otro lado del Atlántico, "reflejados" en el "espejo melancólico" de la luna (444-6). Si para Jiménez la fotografía era "la misma muerte", el retrato de la niña que decidió incorporar al proyecto con el que deseaba definir su posteridad probablemente le recordó su propia muerte. Y es que tanto la fotografía como el texto necrológico de Machado constituyen alegorías que enfrentan al observador con su propia naturaleza perecedera.

Con arreglo a la lectura que hace Benjamin de la obra de Baudelaire, la estructura significativa de la alegoría se basa en la correspondencia de dos planos: eterno y temporal, 
espiritual y secular, duradero y perecedero (Löwy 63-8). Esta estructura también rige la visión ruinosa que ofrece Jiménez de ciertas obras populares: el tiempo, recordemos, espiritualiza estas obras para asimilarlas a "la naturaleza", dejándolas en "un estado más permanente, más 'eterno"” (Metamórfosis 415). Conforme a esta visión alegórica, el paisaje de ruinas que presenta Guerra en España se articula, dialécticamente, en función de un doble régimen de correspondencias entre la obra "duradera" y la obra "perecedera" de Jiménez; esto es, entre la vida póstuma que busca para materiales "eternos" de su bibliografía como los romances populares y la obra "perecedera" que le recuerdan documentos históricos de su biografía como las fotos de la guerra.

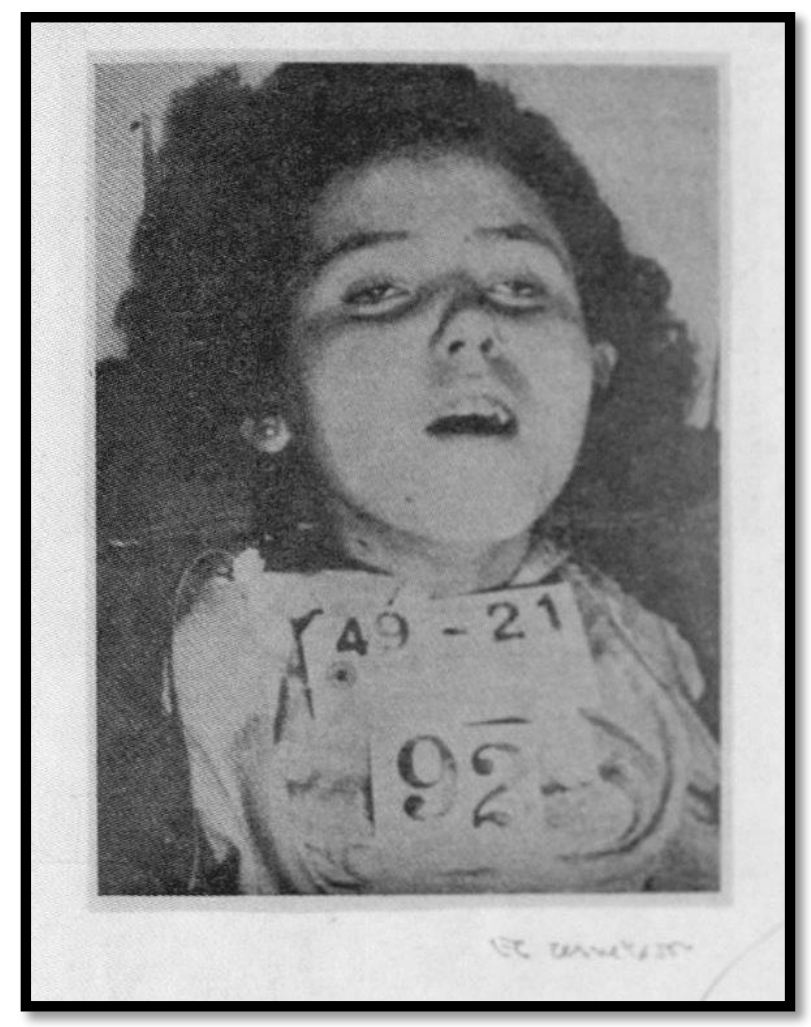

Figure 5. Juan Ramón Jiménez guardó esta fotografía en el archivo destinado a Guerra en España. La nota manuscrita dice "El resultado". Reprinted with permission of Editorial Point de Lunettes.

Asegura Benjamin que la máscara fúnebre no sólo suscita la enigmática cuestión de "la naturaleza de la existencia humana como tal, sino la historicidad biográfica de un individuo" (385). Pasar por alto la tensión que crean en Guerra en España la biografía y la bibliografía de 
Jiménez equivale a quedarse con la "cáscara" de su cadáver, sin atender a la visión del más allá que propone la "máscara", la prosopopeya de su obra. Los ojos, abiertos, de la niña que aparece retratada en "El resultado" se dirigen al frente, pero no nos miran directamente. Como escribió Machado sobre el colectivo anónimo de testigos de la guerra estos ojos verían "desnuda la verdad"; esto es, entreverían un más allá del pasado y del futuro, atestiguando y recordándonos una historia "en lo profundo" a la que, más allá de nuestra propia historicidad biográfica, en definitiva pertenecemos. 


\section{Obras citadas}

Barthes, Roland. Camera Lucida. Trad. Richard Howard. New York: Hill \& Wang, 1981.

Benjamin, Walter. Obras: libro I \& vol.1. Ed. Rolf Tiedemann y Hermann Schweppenhäuser. Trad. Alfredo Brotons. Madrid: Abada, 2006.

Blasco, Javier, y Antonio Piedra, eds. Juan Ramón Jiménez: Premio Nobel 1956. Madrid: Publicaciones de la Residencia de Estudiantes, 2006.

Cadava, Eduardo. Words of Light: Theses on the Photography of History. Princeton: Princeton UP, 1997.

Castellet, J. M. Un cuarto de siglo de poesía española, 1939-1964. Barcelona: Seix Barral, 1966.

Crespo, Ángel. “Introducción”. Guerra en España, 1936-1953. Juan Ramón. Jiménez. Barcelona: Seix Barral, 1985. 5-18.

De Man, Paul. “Autobiography as De-Facement”. The Rhetoric of Romanticism. New York: Columbia UP, 1984. 67-92.

Didi-Huberman, Georges. Cuando las imágenes toman posición. Trad. Inés Bértolo. Madrid: A. Machado Libros., 2008.

Gibson, Ian. Cuatro poetas en guerra. Barcelona: Planeta, 2007.

Gracia, Jordi. La resistencia silenciosa. Barcelona: Anagrama, 2004.

Hardcastle, Anne. “"El documental es un arma cargada de pasado': Representation in Documentary and Testimony". Unearthing Franco's Legacy. Ed. Carlos Jerez-Farrán y Samuel Amago. 148-55. 
Huyssen, Andreas. “Authentic Ruins: Products of Modernity”. Ruins of Modernity. Ed. Julia Hell y Andreas Schönle. Durham: Duke UP, 2010. 17-28.

Jerez-Farrán, Carlos, y Samuel Amago, eds. Unearthing Franco's Legacy: Mass Graves and the Recovery of Historical Memory in Spain. Notre Dame: U of Notre Dame P, 2010.

Jiménez, Juan Ramón. Guerra en España, 1936-1953. Ed. Ángel Crespo. Barcelona: Seix Barral, 1985.

-----. Guerra en España: prosa y verso (1936-1954). Ed. Ángel Crespo; revisada y ampliada por Soledad González Ródenas. Sevilla: Point de Lunettes, 2009.

-----. Metamórfosis. Ed. Antonio Sánchez Romeralo. Barcelona: Anthropos, 1990.

------. Política poética. Ed. Germán Bleiberg. Madrid: Alianza, 1982.

-----. Vida. Volumen I: Días de mi vida. Reconstrucción, estudio y notas de Mercedes Juliá y Mª Ángeles Sanz-Manzano. Valencia: Pre-Textos, 2014.

Labrador, Germán. Res. de Unearthing Franco's Legacy: Mass Graves and the Recovery of Historical Memory in Spain. Ed. Carlos Jerez-Farrán y Samuel Amago. Arizona Journal of Cultural Studies. Vol 14. 2010: 379-83.

López Castro, Armando. El rostro en el espejo: lecturas de Unamuno. Salamanca: Ed. Universidad de Salamanca, 2010.

Löwy, Michael. Fire Alarm: Reading Walter Benjamin's On the Concept of History. Trad. Chris Turner. London; New York: Verso, 2005.

Rancière, Jacques. "Art of the possible: Fulvia Carnevale and John Kelsey in conversation with Jacques Rancière”. ArtForum. Marzo de 2007. Web. 5 Ag. 2014. 
Ricoeur, Paul. Memory, History, Forgetting. Trad. Kathleen Blamey y David Pellauer. Chicago: U of Chicago P, 2004.

Riffaterre, Michael. "Prosopopeia". Yale French Studies. No. 69. The Lesson of Paul de Man (1985): 107-23.

Siles, Jaime. "La guerra civil como referencia explícita". Estados de conciencia. Madrid: Abada, 2006. 227-45.

Trapiello, Andrés. Las armas y las letras: literatura y Guerra Civil (1936-1939). Barcelona: Destino, 2010.

Figure 1. Fotografía, sin título, perteneciente al archivo de Juan Ramón Jiménez destinado al proyecto Guerra en España.

Reprinted with permission of Editorial Point de Lunettes.

Figure 2. "Voces de calidad", artículo de Antonio Machado en favor de Juan Ramón Jiménez, publicado en Valencia el 12 de septiembre de 1937. Este recorte del artículo, publicado en La Habana en 1937, forma parte del archivo de Juan Ramón Jiménez. Reprinted with permission of Editorial Point de Lunettes.

Figure 3. Recorte con la noticia de la muerte de Antonio Machado. Juan Ramón Jiménez lo guardó en el archivo de Guerra en España. La nota manuscrita dice "N[ew] Y[ork]. 39". Reprinted with permission of Editorial Point de Lunettes.

Figure 4. Retrato de Antonio Machado en 1913.

Source: http://www.abelmartin.com/album/album.html

Figure 5. Juan Ramón Jiménez guardó esta fotografía en el archivo destinado a Guerra en España. La nota manuscrita dice "El resultado".

Reprinted with permission of Editorial Point de Lunettes. 